\title{
Rethinking models of architectural research: we don't do objects
}

\author{
Jim Stevens ${ }^{1,2}$, Philip Plowright ${ }^{1,2}$, and Anirban Adhya ${ }^{1,2}$ \\ ${ }^{1} \mathrm{SYNCH}$ Research Group (synchRG) \\ ${ }^{2}$ Lawrence Technological University, Southfield, Michigan
}

\begin{abstract}
Historically, an argument can be made that architectural research was produced internal to firms and manufacturers as proprietary objects or sets of data. The concept of disciplines and professions reinforced the separation of open-sourced knowledge and the application of that knowledge in a commercial context. However, design has rapidly changed from an object-solution profession and is now faced with finding solutions to complex problems within complex systems. The past practice model of client, architect, and final product seems an ill-fit in this new context. The question is how to integrate a critical research process into a professional capacity in which that architectural research needs an inherent and immediate value to be performed or pursued.

The SYNCH Research Group [synchRG] was formed in response to this question. Although research consortiums, design initiatives and research centres exist within many schools of architecture, most operate as a department or extensions of a school of architecture. SynchRG operates in neither private practice nor as a division of the university. Organized as a diverse and fluid association of faculty, students, professionals, and consultants, the synchRG group is focused on a design methodology and philosophical structure rather than a client, site, building, typology, or object. The focus on idiosyncratic or aesthetic solutions to singular problems is set aside in order to provide a collaborative intellectual space for professional based explorations. The paper will examine synchRG's response to current architectural research challenges and illustrate its unique structure as a possible model to be replicated. A dialogue will be initiated on a model for practice aligned with both academia and industry.
\end{abstract}

Conference theme: New methodologies in architectural research Keywords: systems, open source, applied research,

\section{INTRODUCTION}

The use of the term "research" in architecture is illdefined at best and empty semantics at worst, and, at the very least, its application to design and/or practice is misleading terminology. The discussion surrounding research in architecture is not novel to the last few years. The Journal of Architectural Education (JAE) devoted an entire issue in May of 1979 to the question of research in architecture, surveying educators and practitioners. Throughout the 1980 s and 1990s, various articles were published, often with the same language referencing research in architecture as "emerging" (Joroff 1984) or how it was changing the profession (Shibley 1986; Trombley et al 1984). Many papers concern the relationship between academic knowledge and the improvement of practice. The word "research" is presently in vogue both in academia and practice, but one could argue that this terminology has simply replaced what has been known as critical practice without a change to content, methodology or intention.

\section{DOMINANT ISSUES}

\subsection{Architectural research}

Architectural research has traditionally been produced in two distinct domains. First, there is proprietary research, internal to firms and manufacturers. These are either legally protected technology, products, or sets of data and knowledge particular to a market segment that the firms operate in. As this knowledge is important to the maintenance of market share, there is a vested interest to maintain control over this data through secrecy and intellectual property rights. Second, there is academic research, pursued within the confines of architecture schools as ideas discussed in conferences and published in journals. While worthy and important, there is a gap that occurs between traditional pursue of academic knowledge and professional application, with one of the major hurdles being dissemination and access to that knowledge. There are very few sites of professional, free, and open dissemination. InformeDesign, at the University of Minnesota, attempts to address this issue for interior 
design, architecture, landscape architecture, and urban planning by making abstract knowledge available to those professions based on the categories of space, issues, and occupants. However, InformeDesign acknowledges part of their mission is to maintain or reinforce the jurisdictions or boundaries of these professions through the application of abstract, or academic knowledge (InformeDesign 2008).

The concept of disciplines and professions reinforces the separation of knowledge internal to a firm or company engaged in commercial development and the dissemination of that knowledge for other application both within and without the conceptual confines of a profession. It creates a silo mentality. As noted by Meredith Davis, director of North Carolina State University's PhD program in design,

\begin{abstract}
A 2005 Metropolis survey of 1,051 designers, design faculty, and students in all design disciplines found that as much as 90 percent of design research findings are inaccessible to students and faculty, even in their own institutions. There are no design-sensitive research databases or search engines (enter "branding" in the typical library search and you get books on cattle) and most of the research generated by private practice is proprietary. (Heller 2007).
\end{abstract}

There also seems to be a lack of agreement on what exactly research in architecture encompasses. Valid positions can be taken for a range from designing a garage for your neighbor to sociological studies of color perception to the thermal resistance of wall components, among many others. In the design studio and practice, precedent studies of existing projects are within the tradition of "design research." Sustainability is probably one of the most common terms used connected to research today, but now we have two words without clear definitions. And then when "design" is introduced, the issue is confused even more. This openness is seen as a positive element in the creative process, definitions and firm boundaries are resisted in order to allow ideas of progress and development to thrive.

Some arguments place the idea of research as overvalued (Kieran 2007). In academia, the idea of research is resisted in relation to the tenure process. As academics have fought to maintain flexibility over their creative output, scholarly research, as a traditional path to tenure for most academics in hard sciences, is blended with "creative activities" in the design fields. We are not supporting the tightening of these definitions, as there is health in diversity and exploration. We are addressing an aspect of research, applied research, and in particular a model in which to pursue that research that reacts to changes in the organization of knowledge.

A critical shift is occurring, one that should be considered in context of applied research in architecture. This shift is the reframing of design thought in architecture from the discreet object solution to the systems approach. Not only architecture, with its traditional boundaries of aesthetics and distribution of form in space, is affected but all of the design fields. Design has rapidly changed from an object-solution profession, that of the isolated single focus, and is now faced with finding solutions to complex problems within complex systems. These problems and the associated approaches to solutions are very difficult to comprehend in traditional methodological models such as historic architect as the master mason or contemporary architect as the sole designer. The past practice model of client, architect, and final product no longer has the same relevance in this new context. The role of the architects moves beyond the aesthetic jewelry box to instead assemble multidisciplinary teams to pursue less tangible solutions. The question is how to integrate a critical applied research process of professional capacity that uses academic flexibility and is not end-goal focused, yet can also produce solutions both of abstract and concrete natures. The issue is not whether research can be defined, nor whether applied research is being performed but how to approach an old model of practice and academia which is not structured to support a systems-based approach. The entire process, including the dissemination of research, needs to be disconnected from the tenure or proprietary processes, following Creative Commons or Open Source models of design (and architecture) beyond the notion of single architect and object.

\subsection{How objects blind us}

We (the authors) argue that architecture needs to relinquish its fetish on the artifact or the object, and then examine what the effect is on a series of associations. As the focus shifts from the discreet object to a complex assemblage of relationships as the site of inquiry, there are several ramifications. (1) The dominant mode of analysis from Rene Descartes in the $17^{\text {th }}$ century to Jacques Derrida in the late $20^{\text {th }}$ century is predicated on the idea of a closed relationship of binary opposition between two "things". The Western world has been defined as opposing pairs of meaning: mind-body, black-white, life-death, sky-earth, sunmoon, nature-technology, man-animal. Even the most aggressive post-structuralist philosophy didn't eliminate this structure, it simply pointed out the inherent power differential between the members of the pairs, positioning one as a degenerate of the other. These pairs have been instrumental in developing meaning in Western culture and flavor of how our culture perceives reality. (2) As the modern period came into full development, the primacy of meaning was located within the object itself, or, extending this idea to a body of knowledge, within the boundaries of this discipline's discourse. The object and their associated discipline became focused on interiority. These boundaries and territories of a discipline have been guarded and protected as proprietary knowledge. (3)An extension of the focus on the object is a bias it has lent to Architecture. Thus architecture frames itself not as an association of complex elements in space, which includes the social, material, and experiential, but instead as the erection of an object or building. 
When the idea of applied research is introduced into the design process, the idea of system, rather than object, could be said to be the site of possibilities. In the complex layering of engineering, codes, by-laws, budgets, users, public interest, material applications, life safety, human comfort, social values, and aesthetics (to name a few) that are involved in a contemporary architectural design project, simplifying a project down to program or typology seems less relevant and less successful. Furthermore, when these related but diverse layers are engaged as part of the design investigation as a system, solutions occur which would not normally present themselves primarily due to the diverse field of inquiry and small yet significant effects.

System theory recognizes the field as the major site of operation yet it is only by contrasting the field with the object does architecture traditionally manifest. The object supports defined boundaries, as in those traditionally defended by professions. The field suppresses those boundaries. As Neal Leach recognizes, for a thing to lose its boundaries is for that thing to become invisible (Leach,1999). Or to say it in another way, and to quote The Incredibles: "if everyone is special, then no one is special" (Bird 2004). As the boundaries of the field are removed, the recognition of the object as having membership in that particular discipline is brought into question. The question, when shifting from the object to the system, is how do we open the field of influence to other disciplines without losing the integrity of the design language of the profession in which we are operating? Of course, another question could be, is it important to maintain that particular language? The development of system theory not only eliminates the binary pairing as defined positions, it makes traditional boundaries irrelevant to the process. The focus of design and research in architecture is changed. Instead of struggling with arbitrary and culturally fleeting issues of meaning, a systems approach asks how something functions regardless to its traditional category.

There is a further critical shift that occurs when introducing the system instead of the object as the focus of an architectural exploration. The strength of the system is its lack of interest in the firm, fixed and stable boundaries of an object. The strength of the design solution is then found in relevance, rather than the object-focused terms of signification, meaning, truth, or identity. Instead of asking what something means, the question of the signifier in Western metaphysics, the priority of a system approach is, how does it function? Function, in this case, should not be conceived in simplistic operational terms nor is it a fixed category. Function in the system changes, shifts and flexes depending on the association of objects (bodies and machines) in the act of becoming. For example, a bicycle is a machine without a function until it forms an assemblage with a cyclist and a road or path. Only at that point does the bicycle become a vehicle. If the machine "bicycle" forms an association with the "window" in adjacency with the "bicycle store," it becomes an object of commerce. Placed in a gallery and connected to particular viewers, the bicycle becomes a work of art. In each case, depending on the assemblage formed, the function of the bicycle is different (Colebrook 2006). This is difficult to conceive in architectural terms, as function has been traditionally related with typology, program, or economics in fixed categories. Instead, the question can be rephrased: what does it [the system] do? or what is its [the system's] effect?

Ultimately, the alignment brought into design by a systems approach is a way to address contemporary complex problems that are unapproachable through the idea of the discreet object. Applied system thought in architecture is about methodological complexity, not visual complexity. It is a network structure rather than aesthetically driven object. This does not remove the aesthetic nor the object from architecture, it simply displaces its importance. The object, along with parallel issues of aesthetics, cost, function, surface, production, assembly, material, perception, experience, associations, is reintroduced as a form of influence per the field dynamic.

If we extend the idea of system into an operational structure for SYNCH Research Group (synchRG) (as a case study), then alignment and associations which allow for the pursuit of applied research emerge, with applied research at the core of the operations. There is a shift in both authority and hierarchy-stop thinking like a principle, stop trying to own or control something, start acting like a designer.

\section{OPPORTUNITIES AND APPLICATIONS}

\subsection{Applied research centers based in universities} The academic architectural culture has been developing positions towards applied research. Across the globe, schools of architecture are learning to become more innovative in their partnerships, collaborations, and research. Applied research and development of research centers are important phenomena currently seen in universities. There are currently 95 centers of applied research housed in the 57 architecture member-schools of the Architectural Research Centers Consortium (ARCC 2008). This growing body of architecture research centers can be categorized into four categorical research models: (1) faculty led centers focusing on certain concentrations within the department (e.g., MIT SENSEable City), (2) college outreach programs and community design centers (e.g., Lawrence Technological University, Detroit Studio), (3) studio based initiatives (e.g., University of Kansas Studio 804), and (4) independent non-profit practice-based centers (e.g., University of Detroit Mercy, Design Center).

\subsection{Cross disciplinary models}

Many allied disciplines like urban design, urban planning, environmental design, and landscape architecture have invested in developing frameworks and models for applied research in a university context not based on the bias of the object. These discourses have engaged in multi-disciplinary and interdisciplinary 
research models, which can be studied as a possible asset for importing into architectural design. Compared to traditional architecture research, these disciplines have demonstrated more openness, stronger partnerships, and collaborative relationships among various groups. A few of the more prominent examples in urban design, environmental design and planning will be discussed below as case studies.

The Urban Design Project (UDP) is a center devoted to service, teaching, and research in the pursuit of critical practice of urban design at the University of Buffalo School of Architecture and Planning (UDP 2007). The center serves the communities of the Buffalo-Niagara city-region by bringing faculty, professionals, and students together with local governments, community based organizations, and citizens in general, to engage the work of making better places and stronger communities. The work of the Urban Design Project has encompassed independent projects, faculty consultations, student studio projects, and supervised thesis investigations dealing with sites of diverse scale and engaging local, regional, national, and international institutional partners. University alignment is limited to space, heat, software environment, and some computers in return of the overhead costs paid to the university.

The goal of the Center for Environmental Design Research (CEDR) at the University of California Berkeley is to inculcate research in environmental planning and design. Such research, according to CEDR manifesto, is aimed at "increasing the factual content of planning and design decisions and at promoting systematic approaches to design decision making" (CEDR 2008). The center reinforces the broad scope of environmental planning and design through interdisciplinary organization of discourses, resources, and personnel. The research opportunities range from local environments of people within buildings to regionwide ecosystems, from small detail of building construction to large scale urban planning, from the history of the built environment to the design process itself. Center's research and technology transfer projects in the planning and design of urban spaces involve many CEDR faculty from multiple departments. CEDR also manages and edits Places, a prominent journal in the U.S. principally focused on urban design, which acts as a publication outlet for students and faculty in the university as well as institutions and organizations nationally and internationally.

The UM/ULI Real Estate Forum, a joint venture of the University of Michigan (UM) and Urban Land Institute(ULI), is a non-profit volunteer organization dedicated to enhancing real estate education at the professional and academic level. The forum acts as an umbrella organization for other professional organizations interested in promoting scholarship and professionalism in the real estate community. The forum is an integral component of the College of Architecture and Urban Planning Graduate Certificate in Real Estate at the University of Michigan. Through series of lectures, conferences, academic and professional participation in events, and competitions, the forum provides an opportunity for discussion, debate, and dialog regarding real estate design, development, and planning.

The review of these three cross-disciplinary research centers provides some critical insights into the organization structure and modus operandi related to applied research. These could be useful for rethinking the model of applied research in architecture. There is a broad focus and range to the centers. There is generally an interdisciplinary attitude that necessitates collaborative partnerships. Multiple relationships are developed with the community, business, politics, profession, and the academia. The centers are led by a Director and advised by an advisory board. There is involvement of students, often in paid positions, and participation of faculty and professionals as $\mathrm{PI}$ and consultants. Information is disseminated to the academia, profession and the community

\subsection{New opportunities}

Although the applied research centers and cross disciplinary models are making valuable contributions there are still new opportunities that can be explored to address larger issues within the profession. All of the research centers are organizationally aligned to respond to an industrialized set of problems; one that responds to the needs of an individual or group of individuals (client). Design problems are solved and then reintroduced in the following project. As Klaus Krippendorff (2006: xv) describes in The Semantic Turn, functional, aesthetic, and market considerations that justified products of design in the past have been replaced or overshadowed by more social, political cultural and ecological concerns. All of the referenced research centers are organized in a traditional practice model, responding to market considerations of the industrial era. The centers do create relationships with interdisciplinary teams and conduct outreach to the community; taking on projects that the market otherwise would ignore but there is no larger organizational alignment to insure that the solutions can be replicated. They do disseminate findings through the academic community and receive postproject peer review but there is limited co-creation with other research centers, they are not focused or provided with a road map that insures continuity between themselves and their counterparts. In reaction to the need to move away from designing for the market and progressing toward solving the immense problems that face the profession; synchRG turned outside the design profession to reorganize itself affectively.

\subsection{Open source model}

As opposed to community or social based professions referenced above, our (constructed) architectural history has led us to believe that the challenges we face can be solved with a stroke of genius by a solitary designer. Our own lack of progress as a profession and our fixation on fashion and aesthetics have shown that the challenges we now face require a new organizational alignment for our research endeavors. 
One possible resource which could act as a model for organization and cross-disciplinary involvement is open source software development. Open source software is predicated under the assumption that when a program is developed, the source code will be openly distributed and redistributed. Open exchange of ideas and knowledge and an open development process is required. For the open source organizational alignment to work, participants must commit to a common set of rules.

- All software is created with the foundation called source code. This code is made available for free distribution.

- When using the source code developers are then expected to make the new software available to the originator and future developers. This is a critical step to maintain the circular process of development.

- If programmers modify the source code then the new software will be renamed or given a version number. A small modification or a "patch" is often an exception.

- New software that embeds the source code can not place further licensing restrictions that would prohibit future development.

- Distribution of the source code can not be restricted to exclude specific professions, person or groups.

- Software innovations are not proprietary but mutually beneficial.

The open source software community identified early that not one individual could solve all of the problems facing the profession and that it was inefficient for programmers to replicate efforts. This understanding has streamlined the development process and has allowed the community of programmers to respond to a rapidly changing market. Unlike the proprietary development market, the open source organizational alignment depends on an organizational entity that serves to provide direction or a "road map" of goals along with a "community" of developers that continually improve the software. This organizational alignment is best described by James Dixon (2007) as the "beekeeper" analogy. The beekeeper (organizational entity) provides an environment that is attractive for bees (other software developers), an environment that will allow bees to do what they do best-make honey. The beekeeper then sells the honey that funds the further development of the bee farm. The beekeeper and the bees have a symbiotic relationship, one providing the environment and the other providing the work (development). Developers rely on the source code to get their own projects working and the organizational entity (Professional Open Source Software Company POSS) relies on the need for the source code by potential clients. As with any new organizational alignment a new structure for funding and intellectual property was required.

Many open source companies protect intellectual property with copyleft licensing. This is to say, that the originator of the source code reserves the right to dictate how transparent and accessible the source code is to others. Unlike copyright laws that restrict distribution and replication of materials, copyleft allows for distribution and replication as long as the originator of the source code is given credit (GNU 2007). It also requires that the newly created software be licensed under the same copyleft license. Regulation of copyleft software license is typically done with a General Public License (GPL). In the simplest terms it is not "all rights reserved" but "some rights reserved." Each source code developer can customize the GPL but to be considered open source the fundamental ideals of the community must be maintained (It is important to note that some open source community members believe that any act of claiming rights is counter to the community values).

In terms of funding, the source code is not developed for free. It can be assumed that the creator incurred expenses to arrive at a product that is in demand by other development partners. Traditionally proprietary software developers operate on a "go to market" funding model, one that creates in-house research, development, testing and release to the market, or the source code will be licensed from the creator for royalties or another monetary arrangement. The sales of the software are the final judge of the products success. This model presents the software as being an object or artifact, much in the way that a traditional architectural approach positions the building. Open source developers have developed alternative approaches not based on the object. One such approach is to package services to clients as a subscription rather than sell boxes of software. This works well because the software is always being developed and improved by the community as opposed to proprietary improvements delivered through version releases. Open source argues this is a better model because the customers decide when the software needs improvement and the community works to solve the issue. This fluid response to fast-moving problems serves as a lesson to the architecture profession.

Architectural research is not software development (or beekeeping) but there are many benefits to adopting synchronized research relationships. One such option is a direct relationship to "source code." Architecture's source code equivalent is a creatable knowledge base, a collection of research that will benefit the profession through open distribution. Open knowledge will prevent replication of tasks and allow for the continuation of unresolved projects by a diverse group of participants. Within this system lies a potential framework for a new model for architectural research. This new model will respond to the challenges faced by our profession while also recognizing the intuitive process of a new generation of researchers.

Extracting lessons from the open source community in relation to the architectural profession, there are several possible points to be noted. Principally, while open source allows for a fluid and diverse team, lowering barriers for both access and participation, it is still a curated process that is project focused. Oversight is based on production and knowledge, not titles and 
positions, however. For an architectural community, this idea could be extended past the small scale, individual projects to a larger community organizational structure. This structure would connect diverse entities in a curated environment based on tracking projects, knowledge-bases, community issues, technological improvement. The curating entity is the system, not the objects in the system, and provides interface and access to freely distributed knowledge and research.

There are other points that can be extracted from the open source process to apply directly to the architectural community. All participants are encouraged to provide a free exchange of ideas and knowledge. The community must commit to recruiting cross disciplinary members and to identify projects that will incorporate the allied disciplines to remain engaged. Participants commit to opening the research up to the community through an accessible and curated database. Results should be published early and often, they can then be continually updated as new information and research is developed. Think of it as version 0.8 , release 1.0 and update 1.23 . Research participants commit to returning findings to the knowledge base. Peer review will occur in-process to allow for a more fluid research. Finally, check your architectural ego at the door. The community will need to commit to the idea that furthering the profession and the research findings is paramount, not the pristine artifact which is the flavor of the month for the glossy magazines.

\section{5 synchRG/Institute for Advanced Processes}

Based on the idea of systems rather than objects, alternative models of research, organization and ownership, the SYNCH Research Group (synchRG) was formed. The group is a non-rigid organization of faculty, students, professionals, and industry.

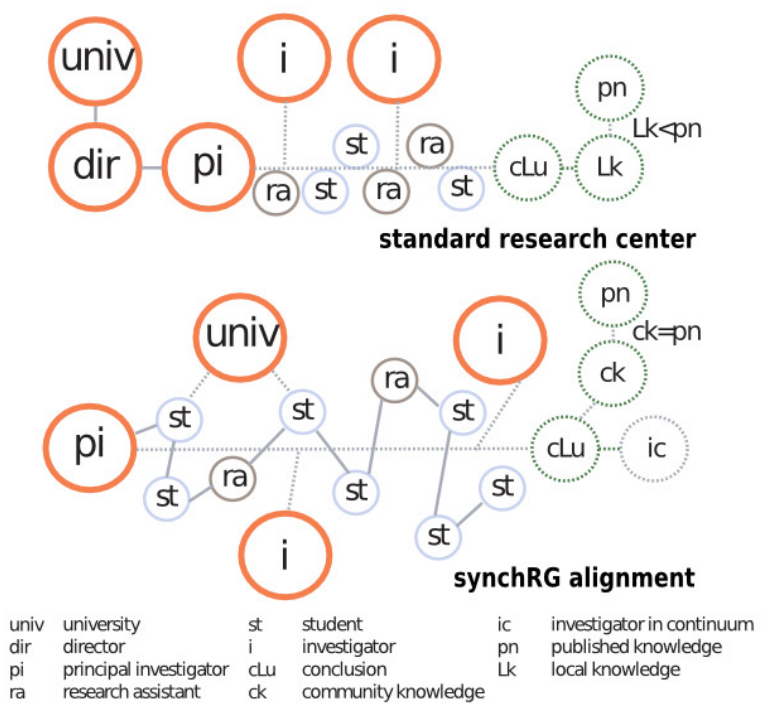

Figure 1: A comparison of referenced research centers' alignment (above) with synchRG's alignment
The group works with the idea of alignment rather than possession. An organizing thread is an approach which dismantles each proposed project into elements and then examines various individual solutions based on the question "what does it do?" in conjunction of its reassembly back into the larger context.

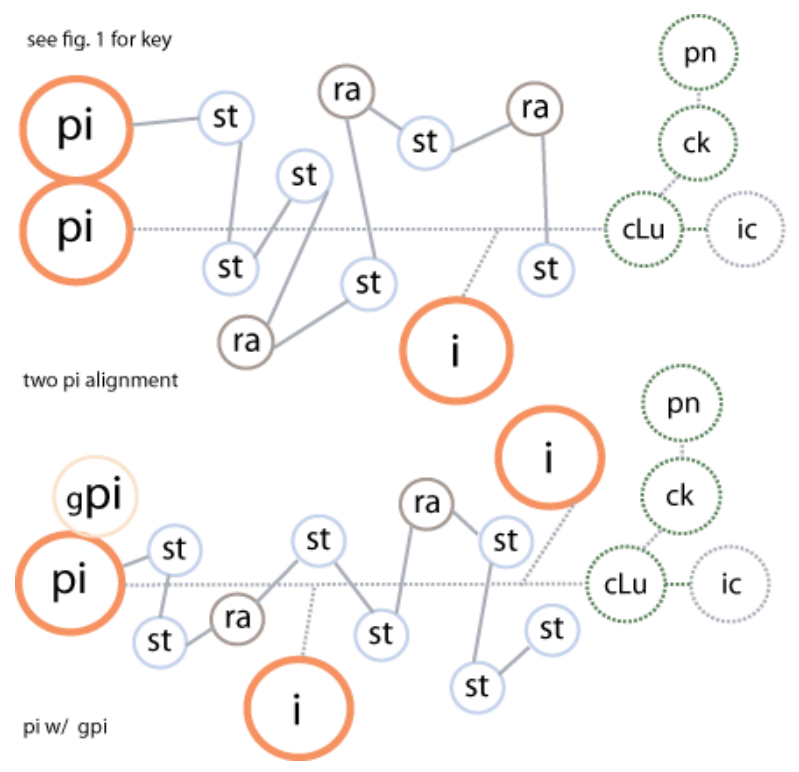

Figure 2: Two of many possible organizational alignments

SynchRG has attempted to set up an organizational alignment with open source community principles. Although operating on a local institutional level, the alignment provides for an effective open research environment. Project alignment defines participants with the following titles:

- Principle investigator: Normally conceives or brings project to the research group and is responsible for the project's completion and findings.

- Investigator: Participates in the project in a supporting role and assists the principle investigator when needed.

- Guest Principle Investigator (GPI): Has all of the duties of a principle investigator but normally is involved only in one specific project.

- Investigator in continuum (IC): Proceeds where a predecessor left off. Predicated on the idea that past investigations will be open and transparent to future research participants.

Various issues occur with a fluid entity like synchRG, specifically around the discussion of resources and funding. While pursuing funding sources for several concurrent projects, it became apparent that the virtual nature of the research group would work against grant applications. While being able to be fluid and assemble teams based on particular strengths, there was a lack of a defined organization or available resources. We needed alignment with another body that would provide 
some of the density expected in traditional grants. To solve some of these issues, synchRG proposed a partnership with Lawrence Technological University. Between the research group and the university a third body would be developed, an Institute. This Institute, vaguely named the Institute for Advanced Processes would be owned by neither the members of the research group nor the university. Instead, it would be an independent non-profit which was aligned with both synchRG and Lawrence Tech. Members of synchRG sit on the Board of Trustees along with Officers of the University to oversee this an independent non-profit, but the resources of the Institute are available to anybody who wishes to make a proposal for their use. There is both financial and legal separation from the research group and the university.



Figure 3: l/flow's organizational alignment

Alternative funding and financial models are being explored within the Institute to develop a core model of applied research. The fundamental question is how to integrate an applied research process into a professional capacity so that research needs an inherent immediate value to be performed or pursued. SynchRG's unique organizational alignment allows for academic freedom, professional efficiency, organizational structure, and transparent findings with duration. The organizational alignment falls short in ability to reach beyond the university. SynchRG envisions that it will be only one of many groups (bees) that openly share knowledge in a larger community. It is this limitation that necessitates the need for a profession wide organizational alignment of research, one that facilities a transparent and open community.

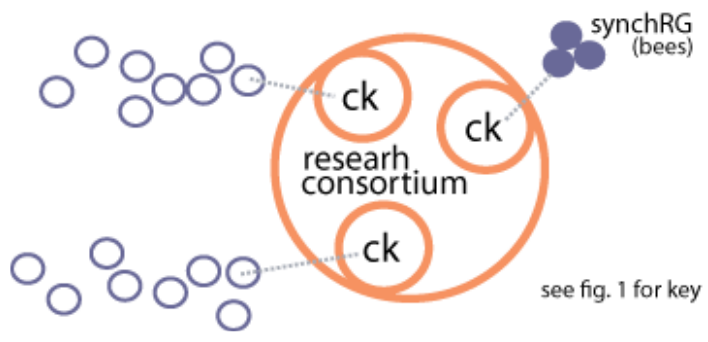

Figure 4: possible "open source" alignment for architecture.

\section{CONCLUSION}

Applied research is a popular discussion within architecture and design at the moment. In academics, however, this focus causes a paradigm shift in how work is done. Any group serious about applied research in architecture has only a few vectors of inquiry on which to focus. These are material studies, physical application research and studies, digital fabrication and computational processes, environment research (psychology/lighting/human comfort), and social research (urban/community). Many of these areas are resource heavy.

Within the late twentieth century debate of modernist morphological understanding (objects) of architecture and the postmodern notions of complexity (systems), there exists a contemporary paradox regarding the relative emphasis of form and function in defining, directing, and practicing architecture. The paradox is thus manifest in the polarization of contemporary theory, practice, and pedagogy of architecture: some commit to social change, but ignore questions of form, material, and spatial order; another is devoted to technology, computation, and morphology, but disregards social and cultural concerns (Hatuka 2007). Present in the design disciplines, the condition of separation and isolation is standard mode of operation in all of general sciences and research fields, Bruno Latour refers to this division between "epistemology, the social sciences and the science of texts" (Latour 1993: 5) as a modern condition, isolating politics, natural phenomena, social effects and studies of power from each other on an intellectual level. Within the design disciplines, Bernard Tschumi (1998) has asserted, this division has created a contradiction, as architects and designers have been unable to reconcile their need to address everyday life with a wish to engage abstract concepts.

To address Tschumi's concern for the gap between the spatial (abstract imagined space) and the social (lived experience) and Latour's desire to reconnect the various elements of our intellectual life, synchRG's proposed model provides a different framework for better understanding and functioning of architectural research. The critical question is why is it a problem that we don't have a good understanding of architectural research? Who cares and why should it matter?

First of all, this research model demonstrates a specific, but critical role of applied research in face of contemporary complex global social, economic, and environmental challenges that architecture as a discipline faces. Stephen Kieran (2007) outlines the development of an ethical architecture that unifies the art of design with the science of performance. He also underlines a research ethic as a necessary prerequisite to develop such an architecture, as does B.D.Wortham (2007) for reinvigorating the idea of research that has become naturalized and ubiquitous cutting across most disciplines. In his "The Way We Think about the Way We Think: Architecture is a Paradigm for Reconsidering Research," Wortham argues that the discipline should seek to become a leader in changing and broadening how research is understood and performed in academe. Twentieth century discussions and debates 
around architectural research are well documented in 1979 and 1990 issues of Journal of Architectural Education (JAE), works of Joroff and Morse (1984), and that of Julia Robinson (1990). The synchRG model, within the context of the twenty-first century, highlights the role of open source model and its experience and appropriation within architecture. This model reinforces the condition where research is "glue"-an interstitial adhesive place that binds theory and practice, that connects the profession and the academia. In the current context, discussed earlier, it is unlikely that much of the architectural research will be conducted solely in the proprietary realm of the profession or within academic confinement. Most of that will happen in "intermediate institutions" like synchRG and will then be enacted in practice and studied in the academic circles. The synchRG model highlights this function of research as a stage of assemblage and enactment. The research model illustrates the powerful role of open construction, use, and reconstruction of knowledge systems irrespective of ownership and typology. This understanding of research center as an interstitial place can be catalytic in promoting shared dialogic space, where things can function in relation to others, in simple sight or knowledge.

Second, the discussion of research in the present capitalist society needs to be in reference to the production and consumption of knowledge. The market seems to be doing a satisfactory job in providing objects and products. But with the continual shift into interconnected complex systems, it often ignores the everyday problems and disregards the importance of functions and processes within these complex systems. There is a two-fold gap between the research, production, and consumption of knowledge. One, research in architecture is engaged predominantly in the proprietary realm or the academic confines. Another, the knowledge produced for consumption and use by people is not designed or poorly designed. Within the constraints of economic interest and political control, human experience, use, and relations are sometimes neglected. Emphasizing systems, performance, and relationships within research, while still involving aesthetics, materials, structure and occupation, as demonstrated by the synchRG research model, is critical to restoring the roles of design and designers in architectural research.

\section{REFERENCES}

Architecture Research Centers Consortium. Inc. 2008. ARCC members. <http://www. arccweb.org/memlst. htm>

Colebrook, Claire. 2006. Deleuze. London: Continuum: London.

Center for Environmental Design Research. 2008. <http://www.cedr.berkeley.edu/default.htm>

Dixon, J. 2007. The Bee Keeper. Pentaho
Corporation.<http://www.pentaho.org/>

GNU Operating System. 2007. Overview of the GNU System/GNU General Public License, Version 3. <http://www.gnu.org/>

Hatuka, T. \& D'Hooghe, A., 2007. After Postmodernism: Readdressing the Role of Utopia in Urban Design and Planning. Places, 19(2), pp. 20-27.

Heller, S. 2007. Is There A Doctor of Design in the House? An Interview with Meredith Davis. $<$ http://www.aiga.org/content.cfm/is-there-a-doctor-ofdesign-in-the-house>

Inform Design. 17 Dec 2008. Mission . <http://www. informedesign.umn.edu/Page.aspx?cld=179\#>

Joroff, M. L. and Morse. S. J. 1984. A Proposed Framework for the Emerging Field of Architectural Research. in ed. James C. Snyder (Ed.). Architectural Research. Van Nostrand Reinhold: New York.

Kieran, S. 2007. Research in design: planning doing monitoring learning. Journal of Architectural Education. v.61, n.1. pp. 27-31.

Krippendorff, K. 2006. The Semantic Turn, Taylor \& Francis Group.

Leach, N. 1999. The Anaesthetics of Architecture. MIT Press, Cambridge.

The Regents of the University of Michigan. 2008. UM/ULI Real Estate Forum. <http://www.umuliforum. $\mathrm{com} />$

Robinson, J. Architectural Research: Incorporating Myth and Science. Journal of Architectural Education v.44.n.1. pp. 20-32.

Shibley, R. G. 1986. Practice and research . Progressive Architecture. v.67, n.12. pp. 49-50.

Trombley, S., Pearman, H., Lawson R.M., and Powell. M. 1984. August. Research: research is increasingly influencing the way in which architecture is practiced. RIBA journal. v.91, n.8. pp. 34-38.

Tschumi, B., 1998. The Architectural Paradox. Oppositions, ed. M. Hayes, Princeton Architectural Press: New York, pp. 224-227.

Wortham, B.D., 2007. The Way We Think about the Way We Think: Architecture is a Paradigm for Reconsidering Research. Journal of Architectural Education. v.61, n.1. pp. 44-53.

The Urban Design Project. 2007. A center for the study and practice of urban design. <http://www.urbandesign project.org/> 